\title{
Self-Employment or Selfless Employment? Exploration of Factors that Motivate, Facilitate, and Constrain Latina Entrepreneurship from a Family Embeddedness Perspective
}

\author{
Soren Newman ${ }^{1}$ (D) Darin Saul ${ }^{1} \cdot$ Christy Dearien $^{1} \cdot$ Nancy Hernandez $^{2}$
}

Accepted: 28 November 2021 / Published online: 2 January 2022

(c) The Author(s) 2021

\begin{abstract}
As the economic and social importance of Latina-owned businesses continues to grow, research is needed on the factors that motivate entrepreneurship among Latinas and that facilitate and constrain their success. This study draws on in-depth interviews and survey data to explore the experiences of Latina entrepreneurs in Idaho, USA, from an embeddedness perspective combining family embeddedness and intersectionality frameworks to illustrate how family and social positioning affects motivations, opportunities, and access to resources. We found Latinas were motivated to start businesses by a range of interacting factors, including centrally a strong sense of responsibility to their nuclear and families of origin. Prominent family motivations included the desire to provide opportunities for younger and older generations and the need for flexibility to manage family and work obligations. Compared to their middle-class peers, working-class Latina entrepreneurs were more likely to need flexibility because they could not afford third-party care for a family member, to experience greater barriers to accessing traditional financing and professional advice, and to be more dependent on family support for their success, although not all had family-based resources upon which they could rely. Latinas struggled to fulfill traditional family role expectations and obligations while assuming the expanded responsibilities of running a business. While a central tension in their lives, this struggle provides the impetus to renegotiate and update traditional gender and family expectations as they navigate role conflict and strain.
\end{abstract}

Keywords Ethnic entrepreneurship · Intersectionality $\cdot$ Women entrepreneurship $\cdot$ Minority women $\cdot$ Family $\cdot$ Hispanic businesses

\section{Introduction}

Entrepreneurship among women has increased substantially in recent decades. In the United States, the number of women-owned businesses increased $21 \%$ between 2014 and 2019 (compared to $9 \%$ for all businesses) to roughly 13 million businesses providing 9.4 million jobs and $\$ 1.9$ trillion in revenue (Ventureneer, 2019). Much of the growth in womenowned businesses is due to the increase in minority-owned

Soren Newman

newman@uidaho.edu

1 Office of Grant and Project Development, College of Agricultural and Life Sciences, University of Idaho, Moscow, ID 83844, USA

2 Margaret Ritchie School of Family and Consumer Sciences, College of Agricultural and Life Sciences, University of Idaho, Moscow, USA businesses, a large proportion of which are owned by Hispanic women or Latinas (IWPR, 2020). ${ }^{1}$ Between 2002 and 2012, the number of Hispanic women-owned firms increased $172 \%$ to 1.47 million (US Census Bureau, 2012), making them the fastest-growing entrepreneurial group in the country. Yet, women-owned and minority-owned businesses have lower success rates than men-owned and nonminority-owned businesses (Cho et al., 2019). Furthermore, self-employed Hispanic women earn less on average than other groups, including self-employed Hispanic men and Hispanic women working as employees (Lofstrom \& Bates, 2009; Zuiker et al., 2011).

\footnotetext{
1 The term "Hispanic" refers to people of Spanish-speaking origin and "Latino/a" refers to people from or descended from Latin America. In the United States, 95\% of Hispanics are of Latin American descent (US Census Bureau, 2018). We use "Latina" when referring to the participants of our research and whichever term is most accurate when citing other sources.
} 
Both the remarkable growth rate and outcome disparities for Hispanic women-owned businesses have important social and policy implications supporting the need for greater empirical exploration. There is a limited but growing literature providing insights into entrepreneurship among Hispanic women. Research shows Hispanic women are motivated to start businesses by multiple considerations often operating simultaneously, including family business experience (i.e., "entrepreneurial capital"), desire for autonomy, career constraints, limited employment options, desire for extra flexible income, self-fulfillment, and commitment to social causes (Cameron \& Cabaniss, 2018; Cho et al., 2019; Valdez, 2016). Much of the Hispanic women entrepreneurship literature uses secondary data to quantitatively describe and explain differences in their outcomes based on human capital variables. For example, Hispanic women entrepreneurs on average have lower educational attainment, have lower English proficiency, and are younger than other entrepreneurs (Lofstrom \& Bates, 2009; Zuiker et al., 2011). Similarly, in a qualitative study, Cho et al. (2019) found lack of confidence in their basic entrepreneurial abilities and knowledge was a barrier for Latina college students interested in starting a business.

Yet, Latinas encounter systemic challenges to starting and operating businesses that extend beyond human capital deficits, requiring examination of social and structural context. The literature on women business owners in general shows women face negative gender stereotypes (Wang, 2019), and lending institutions are more likely to "see women-owned businesses as risky investments with low potential for production, growth, and earning power" (Cameron \& Cabaniss, 2018: 4). Hence, women business owners are more likely to turn to personal savings or family members for funding (Davies-Netzley, 2000). Women-owned businesses are overrepresented in the more-crowded and lower-reward service sector in part because service-sector businesses tend to have lower start-up costs (Marlow \& McAdam, 2013). Hispanic women-owned businesses follow this trend, tending to be concentrated in the less-profitable service sector (Zuiker et al., 2011). Women in general also experience challenges accessing business support and advice (Marlow \& Swail, 2014) and are more likely than men to work in their businesses part-time, from home, or both to accommodate caretaking and housework responsibilities (Marlow \& McAdam, 2013). As such, women commonly struggle to balance family and business obligations (Harvey, 2005; McGowan et al., 2012), although less is known about the interaction of family and business dynamics in the case of Latinas specifically (Wang, 2019).

While the economic and social importance of Latinaowned businesses is increasing, the factors that facilitate and constrain their success remain understudied. Greater understanding of their experiences is critical for designing effective programs and policy that supports Latina entrepreneurs and promotes economic prosperity. More contextualized research is needed to understand their reasons for starting businesses and the conditions that affect their selfdefined success. Considering that most U.S. businesses are family businesses (Aldrich \& Cliff, 2003) and the dominant cultural orientation of Latinas towards collectivist family values (Valdez, 2016), research is needed that examines Latina entrepreneurship in the context of family relationships and resources. This study responds to these gaps and to calls for entrepreneurship research that provides qualitative exploration of contextual and cultural factors (e.g., McDonald et al., 2015). We use in-depth interview and survey data to investigate two questions from an embeddedness perspective: (1) how does the family system-including transitions, resources, and norms-motivate, facilitate, and constrain Latina self-employment, and (2) how are Latina entrepreneurs navigating and negotiating roles and expectations between their business and family spheres?

\section{Embeddedness Theory and Family Dimensions in Latina Entrepreneurship}

Tracing back to Polanyi's (1944) contention that economic life is submerged in social relationships and non-economic institutions rather than operating independently, an embeddedness perspective argues that "economic goals are typically accompanied by non-economic ones related to social context" (McKeever et al., 2014: 226). A social embeddedness perspective examines the agency of the entrepreneur in interaction with structural conditions. For this study, we integrate embedded market and family embeddedness perspectives to gain insight into how Latinas' family dynamics and social positioning affect their entrepreneurial motivations, opportunities, challenges, and access to resources.

Instead of focusing on gender or ethnicity alone as traditional approaches tend to do, the embedded market perspective integrates intersectional analyses to illuminate the ways social location across multiple categories-such as race, ethnicity, class, gender, and nativity—shapes entrepreneurs' experiences and outcomes (Romero \& Valdez, 2016; Valdez, 2008). As Valdez (2011: 155) explains, the embedded market perspective "examines how systems of oppression and privilege...condition the life chances of entrepreneurs from different social locations, even within the same ethnic group." This theory is also useful in highlighting the broader community, economic, and sociopolitical contexts within which entrepreneurship occurs.

Aldrich and Cliff (2003: 574) introduced the family embeddedness framework, noting that while "family and business dynamics are highly interrelated," the ways family dynamics interact with entrepreneurial processes are poorly understood. They identified three interacting characteristics 
comprising a family system: (1) transitions, such as marital status changes, employment, childbirth, and death; (2) resources; and (3) norms, attitudes, and values (i.e., family culture), such as those related to the ways family members interact and "attitudes toward work and family" (590). The framework suggests the family system affects the venture creation process, including resource mobilization, opportunity recognition, and the decision to launch, which then influences the survival, objective performance, and subjective success outcomes of the new venture. In short, the family embeddedness framework explains how family systems impact and condition entrepreneurial activities and posits that engagement in businesses can also affect family resources and lead to "family transitions, and ultimately even change family members' norms, attitudes, and values" (Aldrich \& Cliff, 2003, p. 574).

A growing literature demonstrates the interdependence and interactions of women's businesses with family dimensions (Azmat \& Fujimoto, 2016; Kirkwood, 2012), although very few studies focus on Latinas specifically. While family-based resources such as labor, funding, social networks, and entrepreneurial capital are generally important for small businesses (Sanders \& Nee, 1996), Hispanic entrepreneurs are more likely to rely on family support (Kidwell et al., 2012; Valdez, 2011). Davies-Netzley (2000) found that family-based start-up funding and labor were more important to Hispanic women's business success than they were for non-Hispanic white women. The rural minority women, including Hispanic women, involved in Aspaas's (2004) study seemed to enjoy favorable family attitudes towards their businesses and family resources in terms of psychological support and as-needed labor. However, Valdez (2016) contends the family-based resources that facilitate entrepreneurship are distributed unequally in households based on the social location of each family member. She found women and children in middle-class Mexican-origin households were more likely to provide labor to men's businesses than men and children were to women's businesses, and daughters had fewer opportunities than sons to build entrepreneurial capital or to inherit a family business.

When it comes to family norms, the literature suggests ethnic minority families, including Hispanic families, are more likely than non-Hispanic white families to embrace familism (i.e., "family ideologies and practices that privilege collectivism," which means prioritizing the needs of the family over those of individual family members) (Kidwell et al., 2012; Valdez, 2011, 2016: 1620). However, the extent to which Hispanic families and individuals express a collectivist or individualist ideology varies. For example, Vallejo and Lee (2009) found Mexican-origin respondents who were raised in the middle class were less likely to have a collectivist orientation than those raised in poor families. Additionally, Valdez (2016) supported the contention that familism is gendered in ways that disadvantage Latina entrepreneurs. Valdez (2016: 1633) concludes,

Family roles and responsibilities, especially those associated with traditional gendered expectations, influence the distribution of opportunities and resources within a household. Even as a diverse and collectivist household economy may facilitate enterprise, this structure tends to favour men's entrepreneurial outcomes over women's. Notably, daughters' and wives' care responsibilities and the expectation that they should privilege marriage and childrearing over paid labour contribute to the social and economic advancement of boys/sons and men/husbands within families.

Our study builds upon this previous work to further contextualize and illuminate the interaction of Latina entrepreneurs' family systems and businesses as they navigate and negotiate family culture.

\section{Methods}

\section{Study Area and Background}

We conducted this study in Idaho, a large state $(82,643$ square miles) with a low average population density (19 people per square mile) located in the US Inland Northwest (U.S. Census Bureau, 2019b) (Fig. 1). Idaho's economy has long depended on labor from Latin America, especially to support its sizable agricultural industry (Jones, 2014). Ninety-three percent of the Hispanic population in Idaho is Latino and $85 \%$ are from or descended from Mexico specifically (US Census Bureau, 2018). While Hispanics are more likely than other groups to work in agriculture, they play a growing role in all aspects of the state's economy. The Hispanic population experiences significant income disparities compared to the non-Hispanic population: median household income for Idaho's Hispanic-headed households was about $\$ 10,000$ less per year in 2019 than for non-Hispanic-headed households. In addition, Hispanic women had substantially lower median earnings than other groups for full-time, year-round work: $\$ 28,198$ for Hispanic women compared to $\$ 35,838$ for Hispanic men, $\$ 38,221$ for nonHispanic women, and $\$ 51,053$ for non-Hispanic men (U.S. Census Bureau, 2019a).

Like national trends, Hispanic businesses account for a disproportionate percentage of business and sales growth in Idaho. Between 2007 and 2012, the number of Hispanic-owned businesses in Idaho grew $62 \%$ while non-Hispanic-owned businesses declined 3\%. A higher percentage of Hispanic businesses are owned by women than the general population: while women owned $31 \%$ of 
Fig. 1 Map showing location of Idaho in the United States

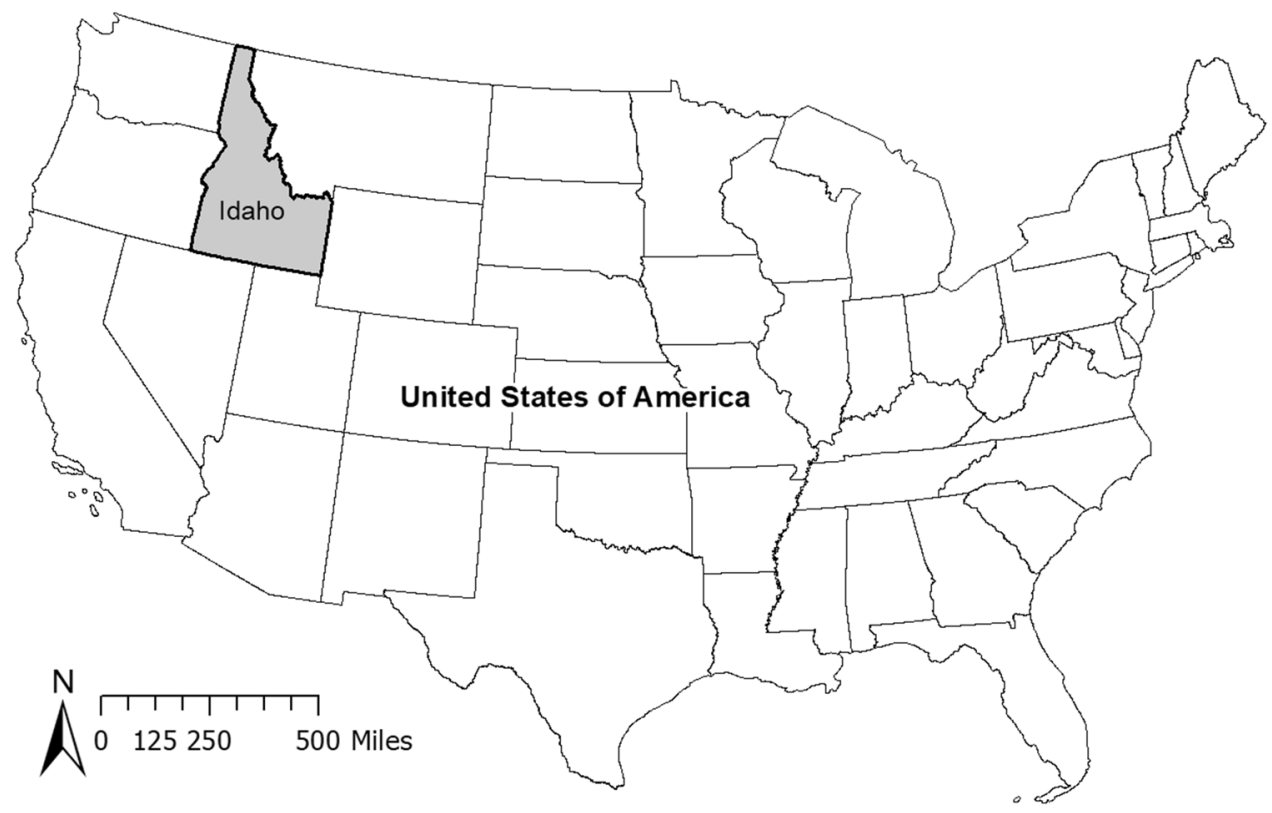

all Idaho businesses in 2012, women owned $41 \%$ of all Hispanic-owned businesses (U.S. Census Bureau, 2012). The starting point for conceptualizing this study was a workshop the second author facilitated with Idaho-based non-profit and agency partners in 2014. Given the growing importance of Latina-owned businesses to community and economic development, these professionals identified the need for research to inform and tailor their programs to this audience. They emphasized the need to better understand the role of family relationships and resources in facilitating and constraining the Latina entrepreneurs in their service populations.

We adopted a sequential mixed-methods approach involving interviews and a survey. We focus on our interview results because qualitative methods were most appropriate to address the primary goals of our research, which were to (1) obtain in-depth insights into a complex phenomenon as experienced by participants and (2) explore questions of "how and why" to "inform practice and policy related to the social norms, practices and contexts of entrepreneurship" (Onwuegbuzie \& Collins, 2007; Ritchie et al., 2013; McDonald et al., 2015: 308). We adhered to rigorous qualitative data collection and analysis according to accepted norms and practices (Glesne, 2016; Onwuegbuzie \& Collins, 2007; Ritchie et al., 2013; Thornberg \& Charmaz, 2014). As Wang (2019: 1782) observed, "both qualitative and quantitative data [related to women and minority entrepreneurship] are rare and hard to collect at least in the United States"; therefore, we also seized an opportunity to conduct a survey of current and aspiring Latina entrepreneurs to expand and complement our qualitative results (Molina-Azorin, 2016). We describe these methods in the following subsections.

\section{Key Informant Interviews}

In March-August 2017, we conducted 15 in-depth interviews involving $18 \mathrm{key}$ informants. We purposefully selected key informants representing small business and economic development organizations, state agencies, non-profits, and other organizations working directly with Latina entrepreneurs. The purpose of these interviews was to broaden the perspectives included in the research and inform development of the Latina entrepreneur interview guide. Seventeen of the key informants worked in Idaho and one worked in Washington State. Interviews were semi-structured with open-ended questions about factors motivating, enabling, and constraining entrepreneurship among Latinas, including family dimensions. Five key informant interviews were conducted in person and ten by phone. These interviews ranged from 30 to $90 \mathrm{~min}$ and were audio recorded with permission and transcribed. The analysis process for the key informant interviews was the same as described subsequently for the entrepreneur interviews.

\section{Entrepreneur Interviews}

From July 2017 to September 2018, we conducted interviews with 57 Latina entrepreneurs. Four interviewees owned businesses in northern Idaho, but the rest were in southern Idaho where the Hispanic population is concentrated. Interviewees were recruited through referral and purposeful sampling to include Latinas representing a variety of business types, family characteristics, and demographics. Interviews were conducted at their business or other place of convenience in their preferred language, with 35 (61\%) conducted in Spanish. Interviews included open-ended questions covering 
business characteristics, motivations, challenges, and family involvement and were semi-structured to allow for unanticipated topics and information to arise. A final set of closedended questions gathered demographic information. Interviews ranged from 30 to $100 \mathrm{~min}$ and were audio recorded with permission, transcribed, and then translated to English, as applicable.

The authors participated in regular meetings to prepare and then debrief, discuss, and interpret observations to ensure quality and consistency. We assigned pseudonyms to interviewees and then analyzed transcripts using ATLAS.ti. The first author led the analysis, which started with an initial inductive coding process to sort segments of data into preliminary codes and categories and to focus further data collection. The co-authors supported this process by conducting independent parallel coding, wherein each researcher independently conducted an initial coding process, and then the results of the code lists and categories were discussed, compared, and integrated to ensure intercoder reliability and a more robust framework (Thomas, 2006). We then used focused coding to refine and organize initial codes into conceptual categories and completed the analysis (Thornberg \& Charmaz, 2014).

\section{Current and Aspiring Entrepreneur Survey}

In 2018, we collected survey data using convenience sampling with participants of an entrepreneurship training program tailored to Latina audiences offered by University of Idaho Extension educators at three locations in southern Idaho. Participants took a paper self-administered survey in their preferred language. We developed the survey questions and answer options based on a literature review and our preliminary interview results. Sixty-five training program participants responded to the survey; however, 15 were not included in our analysis because they were either men or said they do not currently own or plan to start a business. Due to the non-probability sample and exploratory nature of the study, we present descriptive rather than inferential statistics for our survey data.

\section{Findings and Discussion}

\section{Entrepreneur Characteristics}

Table 1 summarizes Latina interviewees' demographic, household, and business characteristics. Their businesses were concentrated in "female-typed" industries (Loscocco \& Robinson, 1991), and 75\% had owned their business for 10 years or less $(n=56)$. Only $9 \%$ had a bachelor's degree compared to $39 \%$ who said they did not have a high
Table 1 Latina interviewee characteristics

\begin{tabular}{|c|c|c|}
\hline Characteristic & $\mathrm{n}$ & $\%$ \\
\hline \multicolumn{3}{|l|}{ Age } \\
\hline$<35$ & 15 & 29 \\
\hline $35-44$ & 20 & 38 \\
\hline $45-54$ & 10 & 19 \\
\hline$\geq 55$ & 7 & 13 \\
\hline \multicolumn{3}{|l|}{ Educational attainment } \\
\hline Some high school (no degree) or less & 22 & 39 \\
\hline High school diploma or GED & 10 & 18 \\
\hline Some college (no degree) & 10 & 18 \\
\hline Technical or associate degree & 9 & 16 \\
\hline Bachelor's degree & 5 & 9 \\
\hline Graduate or professional degree & 0 & 0 \\
\hline \multicolumn{3}{|l|}{ English fluency } \\
\hline I do not speak English & 2 & 4 \\
\hline I speak English, but poorly & 19 & 33 \\
\hline I speak English well & 13 & 23 \\
\hline I speak English fluently & 23 & 40 \\
\hline \multicolumn{3}{|l|}{ Marital status } \\
\hline Never married/single & 3 & 5 \\
\hline Now married & 46 & 82 \\
\hline Divorced/separated & 7 & 13 \\
\hline Widowed & 0 & 0 \\
\hline \multicolumn{3}{|l|}{ Children age $\leq 17^{\mathrm{a}}$} \\
\hline Have no children age $\leq 17$ & 21 & 37 \\
\hline Have $\geq 1$ child under age 5 & 15 & 26 \\
\hline Have $\geq 1$ child age 5 to 12 & 21 & 37 \\
\hline Have $\geq 1$ child age 13 to 17 & 18 & 32 \\
\hline \multicolumn{3}{|l|}{ Business type } \\
\hline Food production & 18 & 32 \\
\hline Retail & 12 & 21 \\
\hline Beauty services & 8 & 14 \\
\hline House cleaning & 2 & 4 \\
\hline Sewing & 2 & 4 \\
\hline Other & 15 & 26 \\
\hline \multicolumn{3}{|l|}{ Years owned business } \\
\hline$<1$ year & 8 & 14 \\
\hline $1-5$ years & 23 & 41 \\
\hline $6-10$ years & 11 & 20 \\
\hline$>10$ years & 14 & 25 \\
\hline
\end{tabular}

${ }^{\text {a }}$ Percentages add up to more than $100 \%$ because some respondents have children in more than one category

school or general education diploma (GED) $(n=56)$, and interviewees ranged in their English fluency. Sixty-three percent were mothers with at least one child aged 17 or younger living at home $(n=54)$. Survey respondent characteristics are summarized in Table 2. 
Table 2 Current and aspiring women entrepreneur survey respondent characteristics, by ethnicity

\begin{tabular}{|c|c|c|c|c|c|c|}
\hline \multirow[t]{2}{*}{ Characteristic } & \multicolumn{2}{|c|}{ Latinas } & \multicolumn{2}{|c|}{ Non-Latina women } & \multicolumn{2}{|c|}{ Total } \\
\hline & $\%$ & $\mathrm{n}$ & $\%$ & $\mathrm{n}$ & $\%$ & $\mathrm{n}$ \\
\hline \multicolumn{7}{|l|}{ Survey language chosen } \\
\hline English & 40 & 12 & 100 & 18 & 64 & 32 \\
\hline Spanish & 60 & 18 & 0 & 0 & 36 & 18 \\
\hline \multicolumn{7}{|l|}{ Ethnicity } \\
\hline Hispanic & 100 & 30 & 0 & 0 & 63 & 30 \\
\hline Non-Hispanic & 0 & 0 & 100 & 18 & 37 & 18 \\
\hline \multicolumn{7}{|l|}{ Age } \\
\hline$<35$ & 37 & 11 & 31 & 5 & 35 & 16 \\
\hline $35-44$ & 27 & 8 & 25 & 4 & 26 & 12 \\
\hline $45-54$ & 23 & 7 & 13 & 2 & 20 & 9 \\
\hline$\geq 55$ & 13 & 4 & 31 & 5 & 20 & 9 \\
\hline \multicolumn{7}{|l|}{ Educational attainment } \\
\hline Some high school (no diploma) or less & 31 & 9 & 6 & 1 & 21 & 10 \\
\hline High school diploma or GED & 21 & 6 & 6 & 1 & 15 & 7 \\
\hline Some college (no degree) & 21 & 6 & 22 & 4 & 21 & 10 \\
\hline Technical or associate degree & 7 & 2 & 17 & 3 & 10 & 5 \\
\hline Bachelor's degree & 17 & 5 & 39 & 7 & 27 & 13 \\
\hline Graduate or professional degree & 3 & 1 & 11 & 2 & 6 & 3 \\
\hline \multicolumn{7}{|l|}{ Marital status } \\
\hline Never married/single & 15 & 4 & 29 & 5 & 21 & 9 \\
\hline Now married & 81 & 21 & 47 & 8 & 67 & 29 \\
\hline Divorced & 4 & 1 & 6 & 1 & 5 & 2 \\
\hline Widowed & 0 & 0 & 18 & 3 & 7 & 3 \\
\hline \multicolumn{7}{|l|}{ Children age $\leq 17^{\mathrm{a}}$} \\
\hline Have no children age $\leq 17$ & 40 & 10 & 67 & 10 & 50 & 20 \\
\hline Have $\geq 1$ child under age 5 & 16 & 4 & 13 & 2 & 15 & 6 \\
\hline Have $\geq 1$ child age 5 to 12 & 52 & 13 & 20 & 3 & 40 & 16 \\
\hline Have $\geq 1$ child age 13 to 17 & 32 & 8 & 27 & 4 & 30 & 12 \\
\hline \multicolumn{7}{|l|}{ Business ownership } \\
\hline Currently a business owner & 33 & 10 & 33 & 6 & 36 & 18 \\
\hline Plans to start a business & 67 & 20 & 67 & 12 & 64 & 32 \\
\hline
\end{tabular}

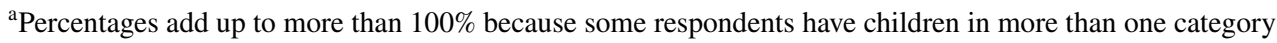

\section{Motivations}

Consistent with the extant literature, Latinas in our study were motivated by multiple economic and non-economic factors interacting simultaneously rather than economic necessity or another factor alone. Figure 2 presents the extent to which survey respondents said they were influenced by factors identified in the entrepreneur interviews and literature. Notably, $86 \%$ of Latina survey respondents said "family support/encouragement" influenced them "a lot" $(n=28)$ compared to $41 \%$ of non-Latina women $(n=17)$.

Interviewees were influenced to start businesses by several types of family transitions, including most commonly parenthood, changes in marital status, and changes in their own or their spouse's health (e.g., four interviewees started businesses when their husbands became ill or injured, affecting their household income). Latina interviewees' family embeddedness was apparent even when the interview did not directly ask them to consider those factors. Two of the most salient themes that emerged from Latina interviews explaining why they started a business were related to their family relationships and responsibilities: the need or desire for flexibility to manage work and family roles and the desire to build a family business. Both themes help illustrate the interaction of Latina entrepreneurship with familism and traditional family gender norms.

\section{Flexibility}

Inés's story illustrates a common theme in our interviews with Latina entrepreneurs: the need or preference for paid work with flexibility to meet family caretaking obligations 
Fig. 2 Extent to which survey respondents said select factors influenced their interest in starting a business, percent of respondents by ethnicity

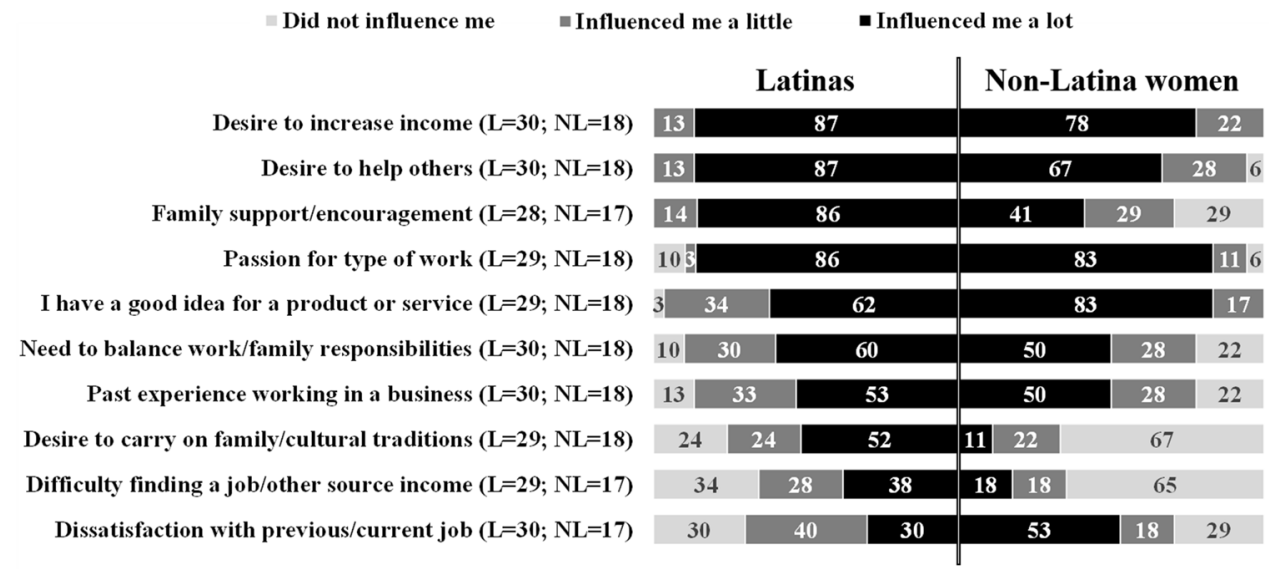

and to prioritize familial relationships. Inés started a food vending business when her husband suddenly became unable to work due to the combination of an occupational injury and chronic illness. With little formal work experience herself and no high school diploma, she decided to start a business capitalizing on the skills she had learned from her mother and developed through her unpaid household labor: "My husband got hurt at work and I don't have the education.... But I know how to make tamales." While it was economically necessary for her to earn money to support her household, her reasons for starting a business rather than seeking wage work were more complicated. She needed work with flexibility to care for her husband (who often needed support throughout the day) and her school-age daughter. Now experiencing role conflict, she also wanted to provide for her family without losing her ability to have time and fulfilling relationships with them:

With the business I can work-not really anytime-but

I know that if I want to, my daughter can be with me.

My husband can be with me. If I have another type of job, I will be with a schedule and then the clock, and I cannot have my daughter helping me or see my husband. I'm a provider in my house, but I need to have a [sic] time with them too.

Being self-employed, Inés can take care of her husband and daughter herself, which saves the family money, gives her peace of mind knowing they are well cared for, and allows her to spend time with them, which she values in itself.

Mothers emphasized that being self-employed allowed them to spend more time caring for their children themselves in part because they preferred to be with their children; however, working-class mothers were more likely to say they needed their children with them because they did not have affordable childcare options they trusted: "I didn't have the money to pay someone to watch the children... [and] I didn't trust I could find someone because not all people will treat them right" (Patricia). Survey results told a similar story with $90 \%$ of Latina respondents saying they were influenced to start a business to some extent by the need to balance work and family responsibilities (Fig. 2). All 15 Latina respondents who had minor children said they were motivated to some extent by the need to balance work and family responsibilities.

Only $23 \%$ of Latina survey respondents said a "non-relative (e.g., a childcare center or nanny)" provides care for their child or children while they work $(n=13)$. Only four of eleven Latina survey respondents with children 12 years old or younger said their child's father helps provide childcare while they work. In one example from our interviews, the interviewee and her husband each had their own business in part because they both wanted flexibility to manage and share parenting and paid work responsibilities; however, in most cases, the assumption and expectation was that the interviewee had primary responsibility to establish a paid work arrangement that accommodated family caretaking needs.

\section{Building a Family Business}

A common motivation among interviewees was the aspiration to build a family business to create opportunity, support intergenerational economic security and mobility, and generally improve the lives of family members:

If I can hit all my [business] goals...I will change... the lifestyle of my whole family. Not only including myself, but I will...leave a legacy for my children, and my children's children. And then also be able to change the lifestyle...that my parents have. (Sandra)

Many focused on creating opportunities for younger generations. Several in the middle-class, like Sandra, expected their children would attend college and bring new skills and experience to the business they had started. For those in the working class, many with limited English skills, it was more 
common to want to provide work for children or grandchildren who the interviewee assumed were unlikely to go to college or have other good options: "I want to involve [my children] so, if they do not study, they can do something to support themselves" (Patricia).

Another theme was the desire to create opportunities for parents:

My question to [my parents was] why didn't they follow their dreams and continue on their business? So, I wanted to show them that it could still happen. Maybe not right now, for them to start their own, but maybe they can join in with mine. (Kora)

These entrepreneurs were first-generation US citizen, college-educated, native English speakers in contrast to their parents. They saw opportunities to capitalize on their immigrant parents' skills, labor, and social networks while engaging the older generation in higher paying and more meaningful work than they could otherwise secure. The desire to build a family business was an especially strong motivation for first-generation high school or college graduates. For some, the focus on building a family business rather than an individualistic enterprise helped them resolve the internalized and sometimes external conflict between their personal aspirations and the values and norms of familism and traditional gender roles.

\section{Managing and Reimagining Family and Work Roles}

In this section, we present our results related to the ways the family system facilitates and constrains Latina entrepreneurship through roles and responsibilities in household labor and through direct involvement in the business.

\section{Household Roles and Support}

While interviewees valued the flexibility of self-employment, meeting role expectations was among the most salient challenges experienced: "I never had time for [my daughters] since they were little... because everything is dedicated to the business" (Amanda). Twenty-one percent of Latina survey respondents identified "family responsibilities" as a significant challenge to their ability to start a business or meet their business goals and another $32 \%$ identified them as a moderate challenge $(n=28)$. This was also a theme that arose from key informants who noted a common barrier for Latina entrepreneurs is the expectation that they are still primarily responsible for managing the household:

Overall, I have seen husbands and children really support the mothers and wives, although there is a lot of strain. The Hispanic woman is still expected to be everything-like maintain the home, support the husband, doing the laundry and cooking — and so that is a lot. (Key Informant 10)

They had observed family conflict related to changing roles and norms as Latinas focused more on business endeavors outside the home: "[My organization is] helping her build her business, which we have known this has sometimes created conflict within families" (Key Informant 3).

The extent to which work-family role conflict challenged individual entrepreneur interviewees varied based on factors such as their access to family and outside support. Not surprisingly for interviewees who were married, how much husbands were involved in household and childrearing work was an important mediating factor. Latina interviewees represented a spectrum of experiences in how household and childrearing labor was shared. Some had little engagement in household labor from their husbands, which compounded their role conflict and strain. The majority of those on this side of the spectrum were working class and had limited English proficiency. For example, Adriana, who had two young children and owned a hair salon, described the tension between her work and family roles and the imbalance between her and her husband's workload like this:

The husband is like another child because you have to be telling him "help me take out the trash, help me wash the dishes, help me with this or that" and they do nothing for themselves. They only think about going to work and getting their check and.... I have to think about...the business, home, and the children-everything.

Overall, married Latina interviewees were more likely than not to say they had some level of partnership in household duties with their husbands regardless of social class or English language skills, and many asserted they were equal partners: "My husband and I both do [the housework]we're 50/50" (Yolanda). Latinas whose children were old enough said their children also helped with household chores. On the other side of the spectrum, some entrepreneurs felt empowered to take on less of the household labor than their family expected:

Being home wasn't an option financially for me... but [my parents and husband] were really upset in the beginning because...the more I worked, the busier I got... and it brought a lot of conflict between the husband and myself because he did not understand.... See, my parents expected me to go to work, come home, take care of the kids, cook, clean, and do the wife duties.... It's not that I dislike doing it, but...my time is better spent making money than cleaning my house... so that I can hire somebody, and pay them half of the amount that I bring in. (Sandra) 
Like Sandra, many were actively redefining their family role and reconciling it with traditional expectations and values. A common emphasis was that their self-employment is compatible with familism and traditional values as they are responding to family needs rather than acting in self-interest. For example, throughout the interview, Sandra framed her business as congruent to fulfilling her traditional role as family caretaker rather than as a detraction from it:

[Building a business is] something that I have mentally ingrained in [my children] since they were babies... whenever they tell me, "Mom, why is it that you work so much, and we don't see you?" Like I said...I am making my sacrifice so if one day my daughter...tells me, "I don't want to work the first five years after I have my child," I am building so she won't have to work. Or, if my son marries and has a wife [who] wants to be a stay-at-home mom and take care of their children, I am making the sacrifice for them. So, yes, it's a sacrifice... but "Listen, this is what we have to do in order to get where we want to get as a family."

Even while constructing alternative roles and identities for themselves and changing family norms in the process, some articulations and attitudes largely reinforced and perpetuated traditional ideologies. Traditional norms and values were modified to meet new and changing conditions.

While key informants saw traditional gender expectations as constraining Latina business ownership and success, they also believed Latino culture has shifted in recent decades, leading to greater willingness among Latino men to take on more household and childrearing work than in the past. Three explanations arose from key informants to explain the perceived change in Latino marital dynamics from less to more egalitarian and that illustrate the interaction of families and businesses with broader socioeconomic and political systems: (1) generational shifts with younger generations embracing egalitarian values, (2) US cultural assimilation, and (3) adaptation to structural conditions where increased marital equity offers greater resilience to adverse sociopolitical and economic circumstances-namely the heightened racism and anti-immigration sentiment they saw many Latino families in Idaho experiencing at the time of the interviews. Two key informants argued family resilience requires each spouse to be able to perform both domestic and business roles in case one of them is detained or deported, highlighting the ways not only race and ethnicity but also nativity and immigration status can shape family and business dynamics.

Evidence from the Latina interviews and survey largely supported key informants' observations related to changing family gender norms. Seventy percent of Latina survey respondents said lack of spouse support/encouragement was not a challenge, although it was a moderate challenge for $15 \%$, and a significant challenge for $15 \%$ $(n=27)$. Interview accounts and survey results suggest that, in some cases, women's families of origin-most influentially, their parents-were more likely to embrace constraining traditional gender norms and attitudes that presented a barrier to their entrepreneurship than the norms, values, and attitudes expressed by their husbands. For example, $11 \%$ of Latina survey respondents identified lack of family support/encouragement as a significant challenge, $32 \%$ as a moderate challenge, and $57 \%$ as not a challenge $(n=28)$. Navigating family-of-origin dynamics was another theme where Latinas used the compatibility of their self-employment with familism and as a way to improve life for the family as a whole (younger and older generations) to justify and leverage family support for their personal ambitions.

While not among the explanations offered by key informants, the most evident explanation for changing family gender norms for working-class Latina interviewees was related to class. Many families did not have a choice-neither spouse made enough money to have a single-breadwinner household, and they often did not have third-party childcare they trusted. Jennifer, a salon owner with a high school diploma and limited English proficiency, illustrated this situation. Her husband was a farmworker whose work allowed less flexibility than her self-employment; however, he wanted to be involved in parenting their two children as much as possible and, because they could not afford childcare, they had little choice but to navigate a partnership. Nonetheless, Jennifer still had disproportionate responsibility for ensuring her family's needs were met:

Like you can see, I have my girls here with me all day. My husband helps me with what he can, [but] he is also working in the fields all day. Sometimes he stays and washes the dishes and helps me. But it is difficult from that perspective: the home, the children, and the business.

In a few cases like this, husbands were farm laborers or had other jobs with long hours and little flexibility, at least seasonally, which helped explain some household division of labor and caretaking disparities. Overall, however, the husband's job was seen as most important and more difficult, even when both were working full time, and the Latina's business was developed to work around it. So, while the traditional norm of women working outside the household for income has changed, the hierarchical relationship prioritizing men's careers largely has not. Interwoven with the want or need for self-employment to manage work and family responsibilities was the shared obligation Latina business owners felt to fulfill, often through considerable self-sacrifice, the unpaid responsibilities necessary to ensure their families' needs were met. They are taking on new roles 
Fig. 3 Extent to which family members help run survey respondents' businesses, percent of respondents who owned a business by ethnicity

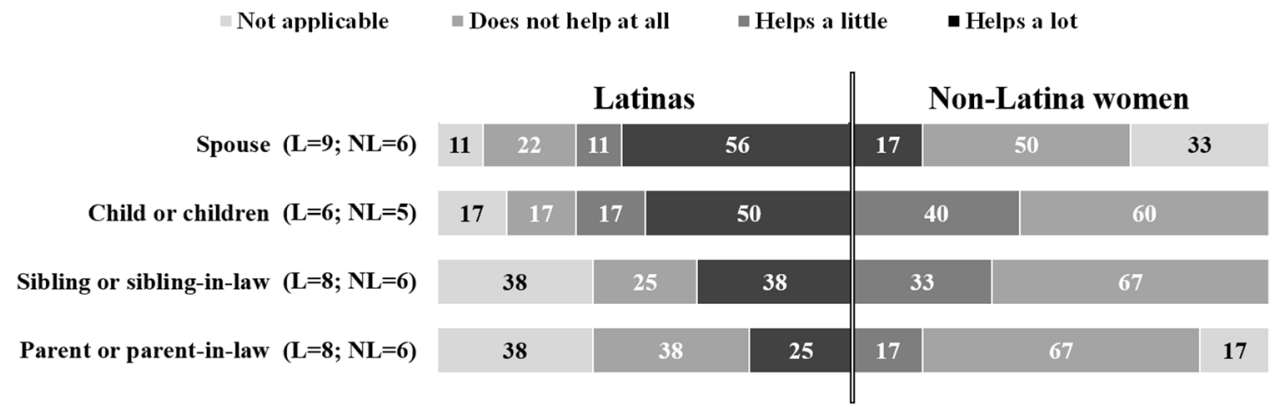

English speakers to complete paperwork or by attending meetings to help with translation. While many Latina interviewees' minor children provided unpaid labor to their businesses in small roles consistent with key informants' observations, most Latina interviewees regardless of class preferred to limit their children's time spent working and rather viewed it as an opportunity for their children to learn skills and responsibility rather than as something the business relied on. All three Latina survey respondents who said their child or children "helps a lot" in running their business had teenage or adult children (Fig. 3).

Key informants also believed that husbands are significantly involved in Latinas' businesses, although Latinas' accounts revealed considerable variability. Some husbands were employed in the business in a similar capacity as the owner herself or provided a complementary skillset with a comparable level of responsibility. Several Latinas characterized their business as a family business ["(My husband) left his other job to help me and, well, it is a "family business' let's say" (Carmen)]; however, more married interviewees described their husband as fulfilling unpaid support roles, such as making small repairs, running errands, and helping on the weekend. Some husbands were not involved in the business at all, typically because they were busy with their own work obligations or because they were spending their non-work hours parenting. Key informants posited husbands are most likely to be involved when they are economically dependent on the business, the business is not in a female-typed industry, and the marriage norms are more egalitarian than traditional.

While family involvement was generally less extensive than many key informants believed, familial resources, networks, and support were crucial in helping many Latinas overcome business ownership barriers. For example, "ability to get a loan" and "access to affordable professional services" were the two factors the greatest percentages of Latina survey respondents identified as significant challenges to starting a business or meeting their business goals. Some Latinas relied on family for both access to capital and advice. 
Fig. 4 If a survey respondent owns a business, what is the extent to which select family members provide advice or ideas that help respondents meet their business goals, percent of respondents by ethnicity

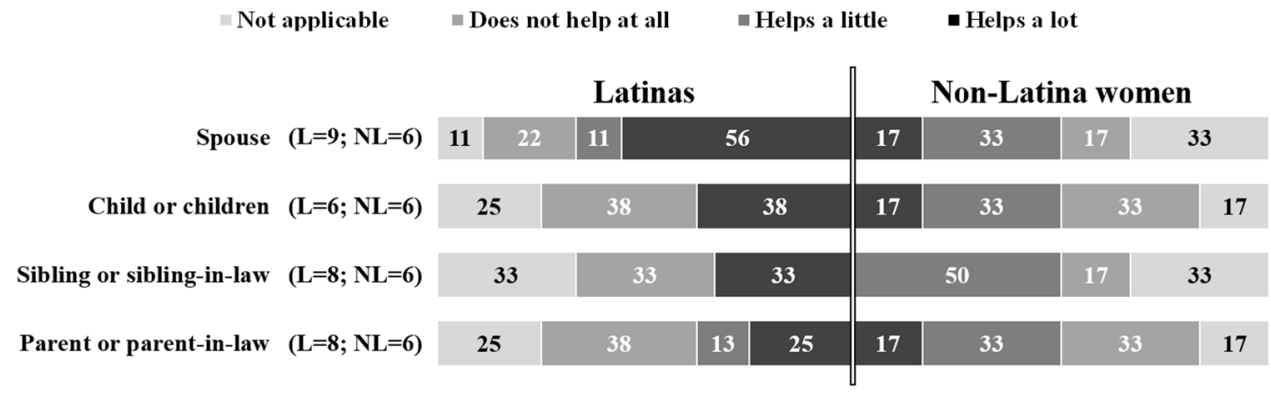

Regarding capital, key informants thought Latina entrepreneurs commonly receive start-up funding from family members rather than traditional financing:

I think a characteristic of Latino families is that they're pretty close knit, and they seem to be more kind of working together, and so they kind of have that support. Instead of relying on going to a bank to get credit, they pool their resources together and help that individual succeed. (Key Informant 6)

Six of the 10 Latina survey respondents who owned a business said their spouse had provided start-up funding (which may reflect that the funds are joint rather than belonging to the husband), and one indicated she had received funding from a sibling. None had received startup funds from their parent/parent-in-law or child. However, many Latina interviewees did not have access to economic resources from family members they could rely on. Those who were divorced or never married could not access support from a spouse, and working-class families had fewer resources to pool. Maria, for example, who had limited resources after getting divorced, was unable to get a loan to start her hair salon:

Family issues, lack of finances-all that were all challenges.... I couldn't get loans because I was homeless. I didn't have anything to show or put down...so it was pretty much on my own, just building it up and saving.

While some had received varying levels of financial support from a spouse or other family member, most interviewees who could not get a professional loan relied primarily on personal savings built slowly over time. Systemic barriers to traditional financing can make Latina entrepreneurship dependent on personal and family resources, which vary widely by socioeconomic and marital status. It also makes aspiring entrepreneurs vulnerable to unsupportive family cultures: "[Family is] one of the places [Latinas] get financing often... but then if your family isn't supportive, well then that's a huge barrier. So, it depends on the family attitude towards the businesswoman" (Key Informant 1).

As with capital, interacting family and class resources influenced Latina interviewees' access to professional services and advice, with those in the middle class enjoying easier access. Camila, who had a bachelor's degree in business and entrepreneurial capital, explained how the professionals who worked for her parents' business were willing to advise her at least initially pro bono:

I'm so blessed to have such a great business background, and connections, and resources: I knew my parents have a lawyer, I knew my parents had an accountant, I knew they had a bank. So, first I went to the accountant, lawyer, and then the bank.

Others-like Elizabeth, a restaurant owner with limited English skills who did not graduate from high school—had a harder time:

I didn't have an accountant. I was afraid an accountant would charge a lot of money. People would tell me an accountant would help, [but] there was one person who billed extra hours. They charged a lot and I had to pay that person too much money and I cried a lot.

Also, in interaction with other social positioning and gender norms, some unmarried Latinas saw themselves at a disadvantage for accessing the professional support needed to start and operate a business:

What organization can I call when I need support? Because, you know what, a lot of women go to their husbands. The husband's friends know someone from work.... What does a person like me do? I have no husband. I have no father here now. My dad was a fieldworker. My dad wouldn't know what to do. I mean, come on. So, it's like, who do I ask? So, then you kind of float around lost for a while figuring it out, wasting a lot of time and money. (Sara)

Figure 4 shows that greater percentages of Latina survey respondents said a family member "helps a lot" in providing advice or ideas that help them meet their business goals compared to non-Latina women respondents. Yet not all Latino families have relevant human and entrepreneurial capital to share. Additional professional support programs need to be developed that support Latinas who 
may otherwise only have access to informal advice from family members.

Latina interviewees said they needed and were interested in professional development in a variety of topics, yet very few had tried to access business development support because, most commonly, they were unaware of available programs, or they did not believe available programs would address their specific need. Key informants also said a barrier for Latinas is not that programs do not exist but that they are not tailored to the audience. Access to professional services was even more of a problem in rural areas, which are less likely to have proximate support organizations.

\section{Conclusions}

The decision to start a business is complex: Latinas in our study were motivated by multiple economic and non-economic factors simultaneously. Gendered family expectations and responsibilities were a common thread through Latina's business motivations and goals on one hand and constraints and challenges on the other. An embeddedness perspective shows that in many cases Latina business ownership is not solely or primarily about personal economic gain or other personal aspirations but about finding creative and flexible ways to meet a variety of family needs. Importantly, self-employment promised flexibility to navigate role conflict and meet expectations of both family and economic spheres in a practical way. While many desired it, the need for flexibility was more prominent for those with limited economic and human capital. Reflecting their social positioning, working-class Latinas were less likely to have access to affordable third-party care for a family member, so were more likely to need work that allowed them to care for family members themselves. Increased access to affordable, high-quality childcare would enable many Latinas to expand their economic participation and potential impact whether through self-employment or other paid work. It would also increase their ability to take advantage of business development support services.

Latina entrepreneurs' motivations, opportunities, and constraints are deeply embedded in their family norms, resources, and relationships. While exercising agency, the entrepreneurs in our study were still embedded in a broader cultural context that values women as family care providers, leading them to push boundaries even while working hard to meet expectations within them. On one level, business ownership allowed Latinas to work without fully subverting traditional gender norms. While a central tension in their lives, this struggle provides the impetus to renegotiate and update traditional gender and family expectations as they navigate role conflict and strain. The family conflict that emerges as
Latinas engage in entrepreneurship provides an opportunity for them to exercise agency in renegotiating family norms and updating family attitudes and values that support their new reality.

Overall, our study supports that more egalitarian family norms help facilitate successful Latina business ownership. Husbands with little or no engagement in household work and childrearing were the exception among participants rather than the norm. At the same time, that men are overall doing more of the unpaid household and parenting labor than they did in the past does not mean their level of responsibility or contribution is equal, although many we interviewed said it was. It makes sense that many Latinas, particularly in the working class, felt role conflict and strain as their self-employment was often intended to provide the household flexibility needed to earn income without relinquishing parenting and household duties.

Social positioning within family and socioeconomic spheres affected the role and importance of family support for Latinas' business success. The family system can support resilience and make business ownership possible; however, our results highlight the limitations of reliance on family support for many as family resources are not distributed equally across or within families (Valdez, 2016). Together, Latinas' accounts demonstrated marital status is a social position that impacts the opportunities and constraints entrepreneurs encounter, with greater advantages experienced by those with supportive spouses in contrast to those with unsupportive spouses or who were divorced, separated, widowed, or never married.

Our finding that some Latinas were motivated to start a business in part to provide opportunities for their parents is interesting considering other research showing the gendered aspects of familism. For example, Ovink (2014, p. 274) found Latino men and women alike viewed their college degrees as "a new resource their generation could access to lift family fortunes," but Latino men viewed going to college as necessary to access the earnings they would need to provide for their future nuclear family whereas Latinas felt a greater sense of obligation to their family of origin. In our study, Latinas were similarly creating businesses to "lift family fortunes" for both their nuclear and family of origin. While the aspiration to build a family business reflected the responsibility Latinas felt for their nuclear and families of origin, it was also a way they were navigating and renegotiating norms: their focus on the greater good of the family was sometimes leverage they used to justify and gain family acceptance for their deviation from traditional expectations.

Some Latinas relied on family-based resources, such as capital, advice, and childcare, because they did not have access to the preferred professional and paid services. Without an intersectional lens, the prevalent belief that Latina entrepreneurs benefit from familism can help 
perpetuate structural disadvantages. Latinas' reliance on family resources, such as capital, represents not only their strong familism but also likely results from their lack of access to professional services due to a wide variety of factors, including discrimination, language barriers, and lack of knowledge, skills, and experience to successfully navigate the process. Familism helps offset the inability to access resources from public and conventional finance and other professional systems but is no substitute for equitable access to non-family resources. Whatever the resources and constraints are for a Latina based on her individual positioning, increasing access to business support, capital, and other resources will enable the success and growth of one of the most dynamic entrepreneurial populations in the United States to directly benefit their families and the communities where they live.

\section{Contributions, Limitations, and Future Directions}

This study contributes new in-depth, nuanced, and exploratory insight into Latina business ownership in the context of family transitions, resources, and culture thereby refining what is known about Latina entrepreneurship and extending the family embeddedness framework for understanding entrepreneurship among this understudied but growing and impactful group (McDonald et al., 2015; Ritchie et al., 2013). It provides deeper insight into how Latinas' family norms, attitudes, and values interact with their business activities, shaping families and businesses. It contributes to the theory of Latina business ownership developing from the literature to help explain national trends (Cameron \& Cabaniss, 2018; Cho et al., 2019), including why many Latinas are starting businesses despite evidence they earn less on average than those who work as employees (Lofstrom \& Bates, 2009). This contextualized research is valuable for designing effective programs and policy that support Latina entrepreneurs and promote economic prosperity. It also illuminates class and other social position-based differences in Latina entrepreneurial motivation and factors that enable and constrain their success and increases understanding of the reasons behind those differences.

This study also has limitations, including that it focuses on Latinas in one state. It also uses non-probability samples, which mean the findings are not statistically generalizable. Future research should compare perspectives and experiences across a broader range of social categories (e.g., gender, race, and ethnicity) and in a variety of geographic contexts. Future research could also build on this study by including family members as participants rather than relying on key informants' and Latinas' accounts of family dynamics alone. Another valuable next step would be to conduct the survey we developed based on the literature and our interview results with a representative sample of Latina business owners in the United States, a specific region, or a specific state to be able to make statistical inferences. Finally, future research should investigate the interaction of family variables, such as structure (e.g., marital status, age of children), transitions, level of involvement, and culture with resource mobilization and financial outcomes using a nationally representative sample of Latina business owners.

Acknowledgements We thank Cynthia Schmeige, Ling-Ling Tsao, and Nancy Deringer for their work in project conceptualization, input on interview guides, and supporting Nancy Hernandez's graduate work; Monica Fisher for helping with preliminary analysis of key informant interviews and helping develop the entrepreneurship experiences survey; Paul Lewin for providing suggestions to strengthen the entrepreneurship experiences survey and reviewing the Spanish version; Surine Greenway and Jacqueline Amende for collecting the entrepreneurship experiences survey data; and Debbie Gray for creating the study area map.

Author Contributions Conceptualization: SN and DS; Data collection and analysis: SN, DS, CD, and NH; Writing-original draft: SN, DS, and $\mathrm{CD}$; Writing - review and editing: SN, DS, CD, and NH; Funding acquisition: DS, SN, and CD.

Funding This work was supported by the United States Department of Agriculture (USDA) Agriculture and Food Research Initiative (AFRI) under Grants 2016-69006-24831 and 2019-68006-29638.

Data Availability Due to the nature of this research, participants of this study did not agree for their data to be shared publicly, so supporting data are not available.

Code Availability Not applicable.

\section{Declarations}

Conflict of interest The authors state no conflict of interest.

Ethical Approval This study was reviewed and certified exempt by the University of Idaho Institutional Review Board (project 16-1112).

Consent to Participate Research participants provided their informed consent.

Open Access This article is licensed under a Creative Commons Attribution 4.0 International License, which permits use, sharing, adaptation, distribution and reproduction in any medium or format, as long as you give appropriate credit to the original author(s) and the source, provide a link to the Creative Commons licence, and indicate if changes were made. The images or other third party material in this article are included in the article's Creative Commons licence, unless indicated otherwise in a credit line to the material. If material is not included in the article's Creative Commons licence and your intended use is not permitted by statutory regulation or exceeds the permitted use, you will need to obtain permission directly from the copyright holder. To view a copy of this licence, visit http://creativecommons.org/licenses/by/4.0/. 


\section{References}

Aldrich, H. E., \& Cliff, J. E. (2003). The pervasive effects of family on entrepreneurship: Toward a family embeddedness perspective. Journal of Business Venturing, 18(5), 573-596.

Aspaas, H. R. (2004). Minority women's microenterprises in rural areas of the United States of America: African American, Hispanic American and Native American case studies. GeoJournal, 61(3), 281-289.

Azmat, F., \& Fujimoto, Y. (2016). Family embeddedness and entrepreneurship experience: A study of Indian migrant women entrepreneurs in Australia. Entrepreneurship \& Regional Development, 28(9-10), 630-656.

Cameron, A. E., \& Cabaniss, E. R. (2018). Forging their own path to the labor market: Hispanic women business owners in North Carolina. Social Currents, 5(4), 369-385.

Cho, E., Moon, Z. K., \& Bounkhong, T. (2019). A qualitative study on motivators and barriers affecting entrepreneurship among Latinas. Gender in Management, 34(4), 326-343. https://doi.org/10.1108/ GM-07-2018-0096

Davies-Netzley, S. A. (2000). Gendered capital: entrepreneurial women in American enterprise (1st ed.). Routledge.

Glesne, C. (2016). Becoming qualitative researchers: An introduction (5th ed.). Pearson.

Harvey, A. M. (2005). Becoming entrepreneurs: Intersections of race, class, and gender at the black beauty salon. Gender \& Society, 19(6), 789-808.

Institute for Women's Policy Research (IWPR). (2020). Women-owned businesses have increased in number, but still face obstacles to growth. Briefing Paper, IWPR \#C488. Retrieved from https://iwpr. org/wp-content/uploads/2020/02/Kauffman-Fact-Sheet-for-layout2-7-2020-1.pdf.

Jones, E. (2014). Latinos in Idaho: Making their way in the gem state. In A. Sowards (Ed.), Idaho's place: A new history of the Gem State (p. 320). University of Washington Press.

Kidwell, R. E., Hoy, F., \& Ibarreche, S. (2012). 'Ethnic' family business or just family business? Human resource practices in the ethnic family firm. Journal of Family Business Strategy, 3(1), 12-17.

Kirkwood, J. (2012). Family matters: Exploring the role of family in the new venture creation decision. Journal of Small Business \& Entrepreneurship, 25(2), 141-154.

Lofstrom, M., \& Bates, T. (2009). Latina entrepreneurship. Small Business Economics, 33(4), 427.

Loscocco, K. A., \& Robinson, J. (1991). Barriers to women's smallbusiness success in the United States. Gender \& Society, 5(4), 511-532.

Marlow, S., \& McAdam, M. (2013). Gender and entrepreneurship: Advancing debate and challenging Myths; exploring the mystery of the under-performing female entrepreneur. International Journal of Entrepreneurial Behavior \& Research, 19(1), 114-124.

Marlow, S., \& Swail, J. (2014). Gender, risk and finance: Why can't a woman be more like a man? Entrepreneurship \& Regional Development, 26(1-2), 80-96.

McDonald, S., Gan, B. C., Fraser, S. S., Oke, A., \& Anderson, A. R. (2015). A review of research methods in entrepreneurship 1985-2013. International Journal of Entrepreneurial Behavior and Research, 21(3), 291-315.

McGowan, P., Redeker, C. L., Cooper, S. Y., \& Greenan, K. (2012). Female entrepreneurship and the management of business and domestic roles: Motivations, expectations and realities. Entrepreneurship \& Regional Development, 24(1-2), 53-72.

McKeever, E., Anderson, A., \& Jack, S. (2014). Social embeddedness in entrepreneurship research: The importance of context and community. In E. Chell \& M. Karataş-Özkan (Eds.), Handbook of research on small business and entrepreneurship (pp. 222-236). Northhampton: Edward Elgar Publishing Inc.
Molina-Azorin, J. F. (2016). Mixed methods research: An opportunity to improve our studies and our research skills. European Journal of Management and Business Economics, 25(2), 37-38. https:// doi.org/10.1016/j.redeen.2016.05.001

Onwuegbuzie, A., \& Collins, K. (2007). A typology of mixed methods sampling designs in social science research. The Qualitative Report, 12(2), 281-316. https://doi.org/10.46743/2160-3715/ 2007.1638

Ovink, S. M. (2014). "They Always Call Me an Investment": Gendered familism and Latino/a college pathways. Gender \& Society, 28(2), 265-288. https://doi.org/10.1177/0891243213508308

Polanyi, K. (1944). The great transformation: The political and economic origins of our time. Beacon Press.

Ritchie, J., Lewis, J., McNaughton Nicholls, C., \& Ormston, R. (2013). Qualitative research practice: A guide for social science students and researchers. SAGE Publications.

Romero, M., \& Valdez, Z. (2016). Introduction to the special issue: Intersectionality and entrepreneurship. Ethnic and Racial Studies, 39(9), 1553-1565.

Sanders, J. M., \& Nee, V. (1996). Immigrant self-employment: The family as social capital and the value of human capital. American Sociological Review, 61(2), 231-249.

Thomas, D. R. (2006). A general inductive approach for analyzing qualitative evaluation data. American Journal of Evaluation, 27(2), 237-246. https://doi.org/10.1177/1098214005283748

Thornberg, R., \& Charmaz, K. (2014). Grounded theory and theoretical coding. In U. Flick (Ed.), The sage handbook of qualitative data analysis (pp. 153-169). SAGE Publications Ltd. https://doi.org/ 10.4135/9781446282243.n11

US Census Bureau. (2012). Survey of Business Owners. Table SB1200CSA01. Data retrieved April 1, 2020, from https://data. census.gov.

US Census Bureau. (2018). American Community Survey, Single-Year Estimates. Data retrieved June 6, 2020, from https://data.census. gov/.

US Census Bureau. (2019a). 2019 American Community Survey, Single-year Estimates. Data retrieved October 6, 2020, from https:// data.census.gov.

US Census Bureau. (2019b). "QuickFacts: Idaho.” Data retrieved July 8, 2020, from https://www.census.gov/quickfacts/ID.

Valdez, Z. (2008). Beyond ethnic entrepreneurship: An embedded market approach to group affiliation in American enterprise. Race, Gender \& Class, 2008, 156-169.

Valdez, Z. (2011). The new entrepreneurs: How race, class, and gender shape American enterprise (1st ed.). Stanford University Press.

Valdez, Z. (2016). Intersectionality, the household economy, and ethnic entrepreneurship. Ethnic and Racial Studies, 39(9), 1618-1636.

Vallejo, J. A., \& Lee, J. (2009). Brown picket fences: The immigrant narrative and 'giving back' among the mexican-origin middle class. Ethnicities, 9(1), 5-31.

Ventureneer. (2019). State of women-owned businesses report. New York

Wang, Q. (2019). Gender, race/ethnicity, and entrepreneurship: Women entrepreneurs in a US south city. International Journal of Entrepreneurial Behavior \& Research, 25(8), 1766-1785. https://doi. org/10.1108/IJEBR-05-2017-0156

Zuiker, V. S., Katras, M. J., Montalto, C. P., \& Olson, P. D. (2011). Hispanic self-employment: Does gender matter? Hispanic Journal of Behavioral Sciences, 25(1), 73-94.

Publisher's Note Springer Nature remains neutral with regard to jurisdictional claims in published maps and institutional affiliations. 